\title{
Effects of Intrapallidal Cannabinoids on Rotational Behavior in Rats: Interactions with the Dopaminergic System
}

\author{
M. CLARA SAÑUDO-PEÑN* AND J . MICHAEL WALKER \\ Schrier Research Laboratory, Department of Psychol ogy, Brown University, Providence, Rhodel sland
}

\begin{abstract}
KEY WORDS cannabinoids; circling; basal ganglia; gl obus pallidus; dopamine
ABSTRACT The effect of unilateral intrapallidal cannabinoid receptor stimulation on rotational behavior in rats was explored. The potent cannabinoid agonist CP55,940 (5 $\mu \mathrm{g} / 0.5 \mu \mathrm{l}$ ) induced ipsilateral turning when microinjected unilaterally into the globus pallidus. The $\mathrm{D}_{2}$ dopamine agonist quinpi role reversed this ipsilateral rotation but failed to affect motor behavior on its own. Finally, the $D_{1}$ dopamine agonist SKF 82958 inhibited movement when administered into the globus pallidus, and this effect was not additive with CP55,940. Synapse 28:27-32, 1998. ๑1998 Wiley-Liss, Inc.
\end{abstract}

\section{INTRODUCTION}

Perhaps, the most striking aspect of cannabinoid receptor distribution in the brain is the extremely high concentration of these receptors in motor control centers, which include the basal ganglia and cerebellum (Herkenham et al., 1991a,b; Mailleux and Vanderhaegen, 1992). Although little is known about the effects of cannabinoids on cerebellar function, a growing literature suggests that the profound effects of cannabinoids on motor function can be accounted for in part by actions of cannabinoids within basal ganglia circuits (Anderson et al., 1995; Miller and Walker, 1995, 1996a,b; Romero et al., 1995, 1996a,b; Sañudo-Peña and Walker, 1997; Sañudo-Peña et al., 1996; Souilhac et al., 1995; Wickens and Pertwee, 1993).

The globus pallidus (GP) and substantia nigra pars reticulata ( $\mathrm{SNr}$ ) possess among the highest levels of cannabinoid receptors in the brain (Herkenham et al., 1991a,b; Mailleux and Vanderhaegen, 1992). However, these output nuclei of the striatum lack detectable levels of mRNA for the cannabinoid receptor (Mailleux and Vanderhaegen, 1992), suggesting that the receptors occur presynaptically on afferent terminals. Anatomic and neurophysiologic data indicate that the striatum and the subthalamic nuclei are two likely sources of presynaptic receptors in the $\mathrm{SNr}$ and GP (Herkenham et al., 1991a; Miller and Walker, 1995; Sañudo-Peña and Walker, 1997; Sañudo-Peña et al., 1996).

In a previous report (Sañudo-Peña et al., 1996), we demonstrated that intranigral administration of cannabinoids in the $\mathrm{SNr}$ provokes contralateral turning behavior. This effect appears to be the result of inhibition of glutamate release from subthalamonigral neurons because cannabinoids inhibit the increased firing in $\mathrm{SNr}$ produced by stimulation of the subthalamic nucleus (Sañudo-Peña and Walker, 1997). Other work indicated that cannabinoids antagonize the inhibitory effect of striatal stimulation on nigral and pallidal neurons (Miller and Walker, 1995, 1996a,b; SañudoPeña et al., 1996). It thus appears that endogenous cannabinoids exert powerful influences on nigral physiology by presynaptic controls over its major excitatory and inhibitory inputs.

Cannabinoid receptors coexist with dopamine D1 receptors on striatonigral and striatopallidal neurons, but they apparently produce opposite effects on second messengers and neurotransmitter release (Graybiel, 1990; Herkenham et al., 1991a; Howlett, 1995; Mackie and Hille, 1992; Mackie et al., 1995; You et al., 1994). Cannabinoi ds antagonized the effects of a D1 agonist in the SNr. A similar antagonist interaction was observed with a D2 agonist, despite the opposite effects of D1 and D2 drugs (Sañudo-Peña et al., 1996). The present work extends this study to the other main output nucleus of the striatum, the GP. As in the previous study of the $\mathrm{SNr}$, the drugs were administered unilaterally into the GP to determine their effects on motor behavior with the aim of clarifying the nature and site of motor actions of cannabinoids in relation to dopaminergic influences.

\section{MATERIALS AND METHODS}

Male Sprague-Dawley rats (Charles River Laboratories, Wilmington, MA), $250-300 \mathrm{~g}$ at the time of sur-

*Correspondence to: M. Clara Sañudo-Peña, Department of Psychology, Brown University, P.O. Box 1853, 89 Waterman Street, Providence, RI 02912. email: Clara@Poppy.Psych.Brown.Edu

Received 27 December 1996; accepted 15 April 1997 
gery, served as subjects. They were individually housed in metal cages in a temperature-regulated $\left(22-23^{\circ} \mathrm{C}\right)$ room with food and water freely available. Artificial lighting was provided from $0700 \mathrm{~h}$ to $1900 \mathrm{~h}$.

On the day of the surgery, the animals were anesthetized with sodium pentobarbital $(50 \mathrm{mg} / \mathrm{kg})$ and placed in a stereotaxic frame. A 24-gauge guide cannula constructed from stainless steel hypodermic tubing was implanted so that its tip was $4.0 \mathrm{~mm}$ above the center of the left GP $(0.7 \mathrm{~mm}$ posterior, $2.7 \mathrm{~mm}$ lateral, $6.9 \mathrm{~mm}$ ventral from bregma and the skull surface). The cannulas were fixed to the skull with stainless steel screws and dental acrylic. Stainless steel stylets kept the cannulas seal ed.

After at least three days of recovery, animals were tested for turning behavior after receiving a intrapallidal injection of a drug or combination of drugs. Drugs were injected ( $0.5 \mu \mathrm{l}$ over a two-minute period); the injection cannula (31-gauge stainless steel tubing) was left in place for an additional $30 \mathrm{sec}$ before removal. After the injection, the stainless steel stylet was replaced in the guide cannula, and each animal was placed in a rotometer. An adjustable elastic harness fitted around each animal was connected by a metal cable to an optical transducer that encoded the position of the rat as a binary signal. A computer interfaced to the transducer calculated the number and direction of half-turns per minute for each animal during a 30-min testing session. Each rat was tested once.

Sodium pentobarbital was obtained from Abbot Laboratories (North Chicago, IL). The potent cannabinoid agonist CP 55,940 was generously provided by Pfizer Inc. (Groton, CT). All microinjected drugs were dissolved in 60\% DMSO (Sigma Chemical Co., St. Louis, MO). The D1 dopamine receptor agonist SKF 82958 and the D2 dopamine agonist quinpirole were obtained from Research Biochemical s International (Natick, MA). All other drugs and chemicals were obtained from the Sigma Chemical Co.

After behavioral testing, rats were perfused transcardially with a $10 \%$ formalin solution while under deep anesthesia. Brains were fixed in a $30 \%$ sucroseformalin solution and frozen. Coronal sections $(40 \mu \mathrm{m})$ were stained with cresyl violet and examined under a microscope to localize injection sites. I n all studies, only the data from animals with correct cannula placements (Fig. 1) and mi nimal nonspecific damage were included.

Rotation after intrapallidal injections of the cannabinoid agonist CP 55,940 (5 $\mu \mathrm{g})$ was examined. We also tested the effect of coadministration of CP 55,940 and the D1 agonist SKF $82958(10 \mu \mathrm{g})$ on the rotation induced by administration of either single compound and the effect of the D2 agonist quinpirole $(2.5 \mu \mathrm{g})$ on the turning induced by intrapallidal administration of CP 55,940.

Net contralateral half-turns (contralateral minus ipsilateral) were used in all the data analyses. All data in this study were anal yzed together. Dueto heterogeneity of variance, the data were analyzed by using a nonparametric one-way Kruskal-Wallis test. Post hoc comparisons were made by using the Mann-Whitney test.

\section{RESULTS}

An overall analysis of variance revealed that the various drug combinations administered into the GP produced markedly different effects on rotational behavior: Kruskal-Wallis test $(\mathrm{H}=26.49, \mathrm{P} \leq .0001)$. Rats injected with CP 55,940 (5 $\mu \mathrm{g})$ showed significant ipsilateral rotation compared with the vehicle group (Mann-Whitney test $\mathrm{P} \leq .04$; Figs. 2 and 3 ).

Injections of SKF $82958(10 \mu \mathrm{g})$ into the GP induced significant ipsilateral rotational behavior (MannWhitney test $P \leq .002$; Fig. 2). The unilateral administration of the dopamine D1 agonist into the GP produced catalepsy as measured in the bar test. Whereas all animals that received vehicle descended from a horizontal bar immediately, all animals treated with the D1 agonist exhibited descent latencies $>1 \mathrm{~min}$ (Wilcoxin Signed Rank Test: P $\leq .001$ ). Coadministration of the D1 agonist with the cannabinoid agonist produced significant ipsilateral turning $(\mathrm{P} \leq .002$; Fig. 2 ), which was similar in magnitude to that induced by the $\mathrm{D} 1$ agonist alone.

In contrast to the D1 agonist, the D2 agonist did not produce circling when micro-injected in the GP (Fig. 3). However, coadministration of quinpirole with the cannabinoid reversed the contralateral rotation induced by the administration of the cannabinoid agonist alone $(\mathrm{P} \leq .04$; Fig. 3).

\section{DISCUSSION}

In this study, the unilateral microinjection of cannabinoid agonist CP55,940 into the GP produced ipsilateral turning behavior. These data suggest that the cannabinoid agonist inhibited pallidal neuron firing. This effect was antagonized by intrapallidal coadministration of a dopamine $\mathrm{D} 2$ but not a D1 receptor agonist. In addition, we observed ipsilateral turning after unilateral pallidal microinjections of the dopamine D1 receptor agonist SK F 82958, whereas the dopamine D2 receptor agonist quinpirole failed to induce significant turning.

The ipsilateral turning produced by intrapallidal administration of cannabinoids probably results from inhibition of pallidal neurons. This conclusion is consistent with the finding that inhibition of pallidal neurons with phencyclidine, a noncompetitive NMDA receptor antagonist, leads to ipsilateral turning, and electrical or chemical stimulation of the GP leads to contralateral turning (Aiko et al., 1988; Herrera-Marschitz et al., 1987; Slater et al., 1980; Yamaguchi et al., 1986). Pallidal neurons are inhibited by systemic and micropressureadmi nistration of cannabinoid agonists (Miller 


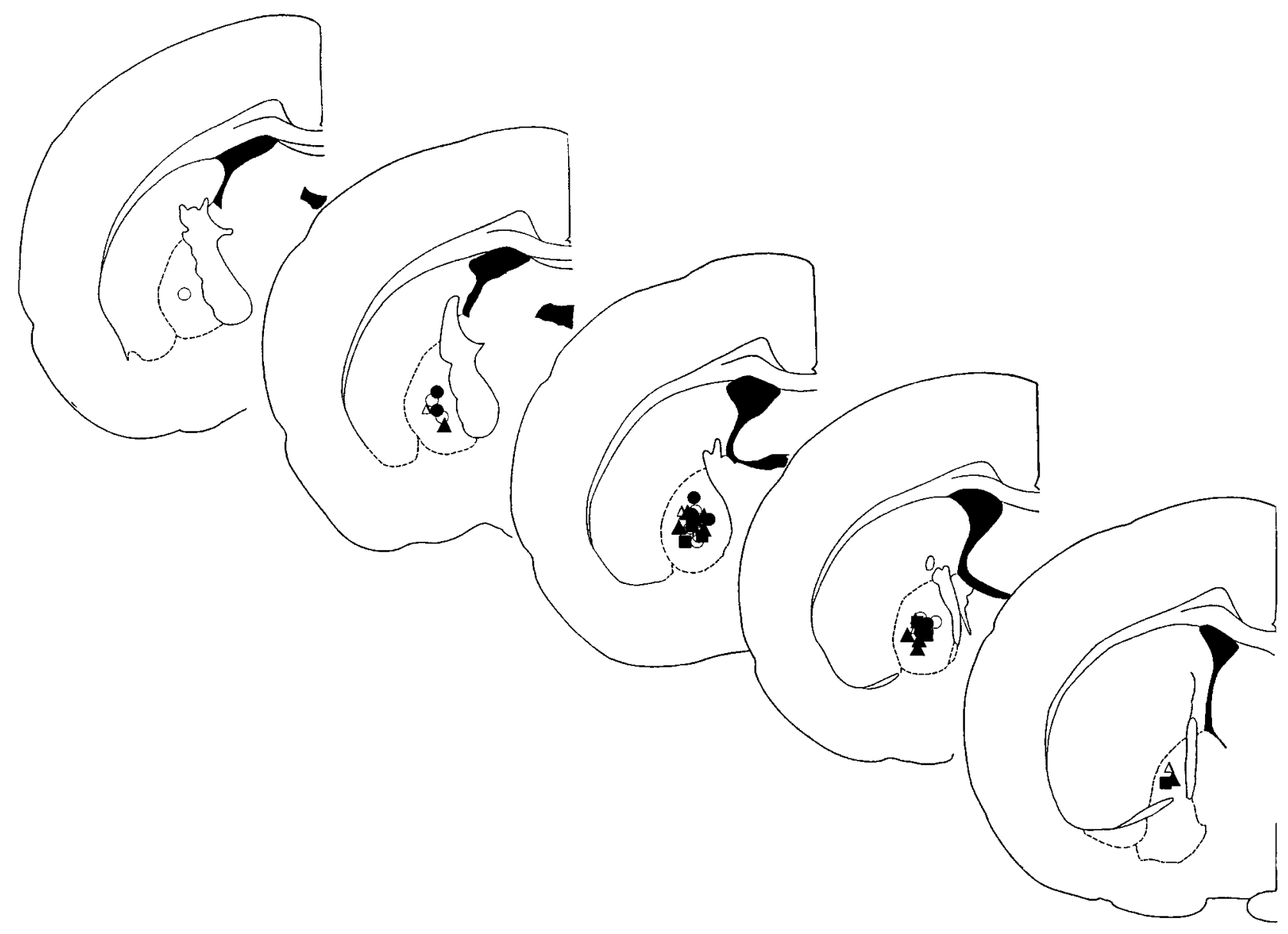

Fig. 1. Diagrammatic representation of the localization of guide cannulae tips for intrapallidal administration of $(O)$ vehicle, $(\bullet)$ the cannabinoid agonist CP55,940, $(\square)$ the dopamine $D_{1}$ agonist SKF 82958, ( $\boldsymbol{\square})$ SKF $82958+\mathrm{CP} 55,940,(\triangle)$ the dopamine $\mathrm{D}_{2}$ agonist quinpirole, and $(\boldsymbol{\Delta})$ quinpirole + CP55,940.

and Walker, 1996a,b), and cannabinoids enhance the catal epsy produced by pallidal microinjections of GABA agonists (Wickens and Pertwee, 1993). These findings are consistent in indicating that cannabinoids inhibit pallidal output neurons and that this would be expected to result in ipsilateral turning, which was observed.

As noted above, inhibition of the excitatory input from subthal ami c nucleus termi nals appears to account for the turning behavior produced by microinjections of cannabinoids in the substantia nigra (Sañudo-Peña and Walker, 1997; Sañudo-Peña et al., 1996). A similar mechanism may account for the actions of cannabinoids in the GP, because it also receives a major excitatory input from the subthalamic nucleus. In support of this possibility, glutamate antagonists enhanced the catalepsy induced by cannabinoids (Kinoshita et al., 1994) and induced ipsilateral rotation when injected into the GP (Yamaguchi et al., 1986).

Little work has been directed at understanding the relationship between dopamine D1 receptors in the GP and motor behavior. The striatum is the main source of
D1 dopamine receptors to the globus pallidus (Herkenham et al., 1991a), but mRNA for the dopamine D1 receptor is found also in pallidal neurons (Mansour et al., 1991). Therefore, the dopamine D1 agonist could enhance GABA release by an action at striatopallidal terminals or intrinsic pallidal neurons (You et al., 1994). This would cause inhibition of pallidal output neurons and thus lead to i psilateral turning. Dopamine D1 and cannabinoid receptors are colocalized on striatal terminals (Herkenham et al., 1991a; Mansour et al., $1990,1992)$ and apparently produce oppositeactions on neurotransmitter rel ease (Graybiel, 1990; Herkenham et al., 1991a; Howlett, 1995; Mackie and Hille, 1992; Mackie et al., 1995; You et al., 1994). Therefore, one would expect to see opposite actions of these two classes of agonists and antagonistic interactions when the two are coadministered.

Whereas an antagonist interaction between dopamine D1 and cannabinoi d receptors occurred in the SN $r$ (Sañudo-Peña et al., 1996), which exhibits a similar colocalization, neither opposite actions nor an antago- 


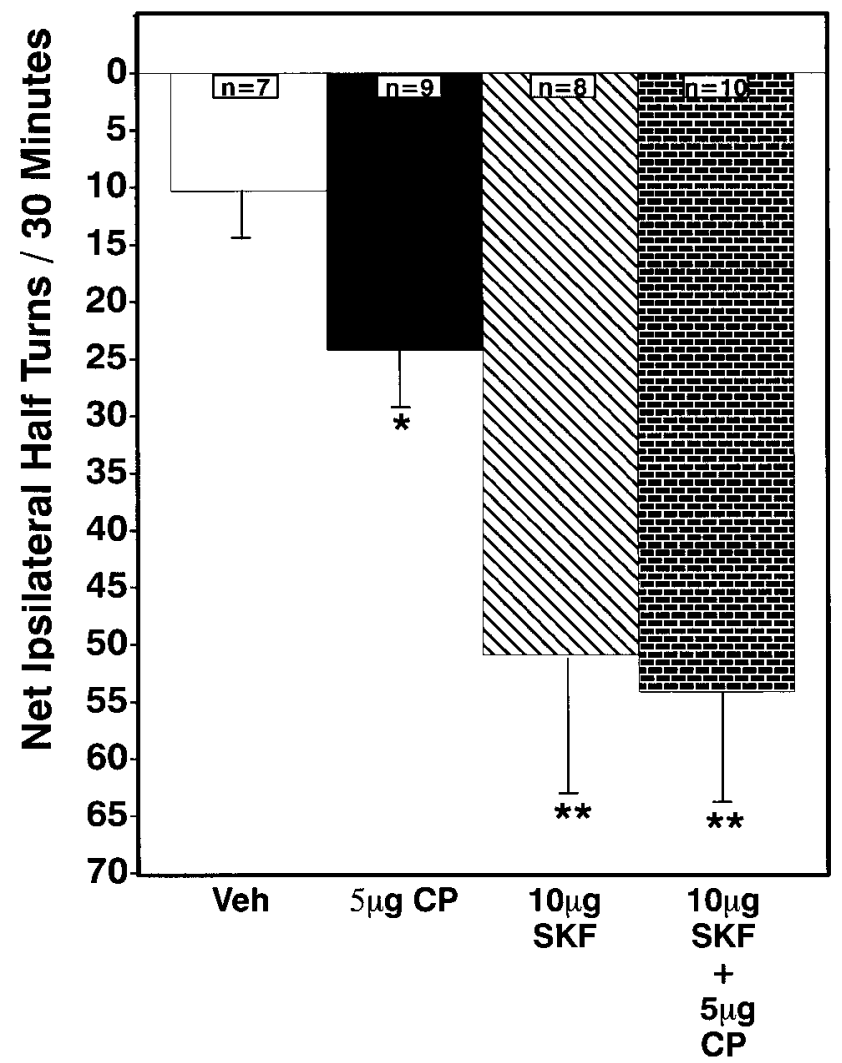

Fig. 2. Effects on turning behavior caused by unilateral microinjections of the cannabinoid agonist CP55,940 alone or together with the $D_{1}$ dopamine receptor agonist SKF 82958 into the globus pallidus (*significantly different from the rest of the groups, **significantly different from the vehicle, CP55,940, quinpirole, and quinpirole + CP55,940 groups, $\mathrm{P}<.05)$. The administration of the cannabinoid or the dopamine $\mathrm{D}_{1}$ agonist induced ipsilateral turning. The administration of the cannabinoid agonist together with the $D_{1}$ dopamine receptor agonist had the same effect on turning behavior as the administration of the $D_{1}$ dopamine receptor agonist alone.

nistic interaction was found in the GP. Perhaps the low density of D1 receptors compared with cannabinoid receptors accounts for the negligible interaction between them in the GP. This favors the idea that the main effect of the D1 agonist may be to rel ease GABA from terminals that are lacking in cannabinoid receptors, whereas the cannabinoid agonist inhibited neurotransmission at subthalamopallidal terminals, which are lacking in dopamine D1 receptors (Mansour et al., 1990, 1992). This could account for a prevalence of inhibition of pallidal neurons, which would be reflected as ipsilateral turning. The lack of any synergistic interaction between the D1 ligand and the cannabinoid may be the result of a ceiling effect. Further studies using a range of doses would help clarify this.

At first glance, the observation of marked ipsilateral turning and a catal eptic response in the bar test would appear to pose a contradiction. However, previous work has shown that locomotion and catalepsy are not part of a continuum in which catalepsy is a maximal suppres-

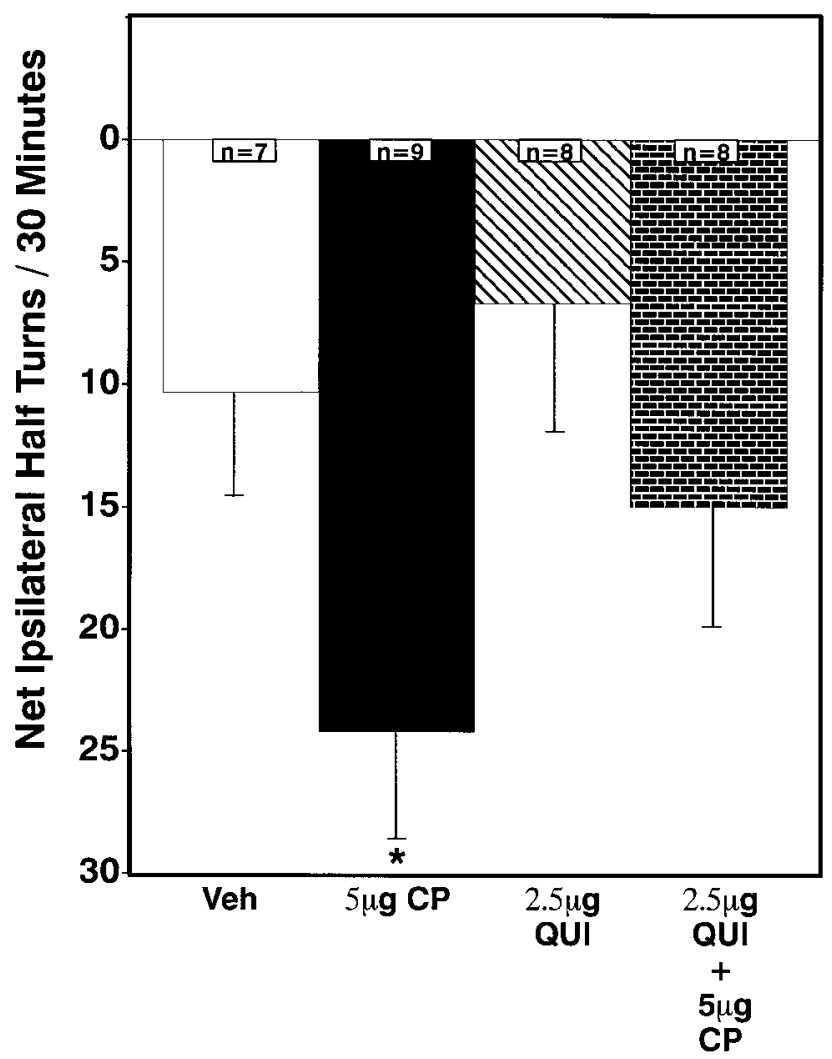

Fig. 3. Effects on turning behavior caused by unilateral microinjections of the cannabinoid agonist CP55,940 al one or together with the $\mathrm{D}_{2}$ dopamine receptor agonist quinpirole into the globus pallidus (*significantly different from the rest of the groups, $\mathrm{P}<.05$ ). The $\mathrm{D}_{2}$ dopamine receptor agonist significantly reduced the ipsilateral turning induced by the cannabinoid agonist but had no positive effect on turning behavior.

sion of motor responses (Klemm, 1989). Rather, catalepsy appears to be a form of "active immobility," which may involve failure of initiation of complex motor acts. Therefore, the presence of cataleptic responses in the bar test and ipsilateral turning are not incompatable and have, in fact, been observed with other drugs (Sukul et al., 1988). In addition, these findings offer a likely explanation for the failure of dopamine D1 agonists to reverse the cataleptic effects of dopamine antagonists (Vacherri et al., 1986).

Dopamine D2 receptors occur on several neuronal types within the GP. They are located mainly at striatopallidal terminals, where they are colocalized with cannabinoid receptors (Herkenham et al., 1991a; LeMoine and Bloch, 1995). However, dopamine D2 autoreceptors may also exist on the terminals of dopaminergic neurons that innervate the GP (Lindvall and Bjorklund, 1979; Pucak and Grace, 1994), and they may occur on intrinsic pallidal neurons as well (Mansour et al., 1990; Meador-Woodruff et al., 1989). Dopamine D2 receptors located on striatopallidal terminals apparently inhibit GABA rel ease from theseterminals (Gray- 
biel, 1990; Pucak and Grace, 1994; Santiago and Westerink, 1991; You et al., 1994), thereby indirectly activating pallidal neurons. A similar effect of the cannabinoid would be expected because cannabinoids inhibit striatonigral neurotransmission (Miller and Walker, 1995; Sañudo-Peña et al., 1996). However, striatopallidal terminals are quiescent (Wilson, 1993), which may explain the inactivity of the quinpirole when administered alone. If this explanation were correct, it would imply that actions of the D2 drug on intrinsic neurons or on autoreceptors were also below that needed to produce an effect on behavior.

The dopamine D2 agonist antagonized the ipsilateral turning induced by thecannabinoid. Thegeneral conclusion of opposing actions of cannabinoid and dopamine D2 agonists is consistent with the ipsilateral rotation produced by intrapallidal injection of neuroleptics, which are thought to act as antagonists mainly at the dopamine D2 receptor (Costall et al., 1972). It may be that the excitatory effect of the D2 agonist on pallidal neurons predicted from the activation of D2 receptors on striatopallidal neurons was not strong enough to affect behavior when administered alone. However, it may still have opposed the action of the cannabinoid on turning. Of course, with the multiple sites of action of D2 agonists within the pallidum, other possibilities should be considered in future work.

The present report that cannabinoids inhibit movement through their action in the GP is in agreement with a previous study showing loss of cannabinoid receptors in the GP of Huntington disease patients in early stages of the disease (Richfield and Herkenham, 1994). A loss of inhibition of the pallidal output neurons is associated with the chorea observed in early stages of the disease (Albin et al., 1989). The finding that cannabinoids in this circuitry exert behavioral effects that are similar to those of D1 agonists but opposite to those of D2 agonists may suggest novel therapeutic drug treatments for neurodegenerative and motor disorders.

\section{ACKNOWLEDGMENTS}

The authors express their gratitude for the financial support provided by the National Institutes of Health (DA10043, NS33247, MH 01083). We thank Dr. Saul B. Kadin (Pfizer, Grotton CT) for the gift of CP55,940 and Cara Anselmo for editorial assistance.

\section{REFERENCES}

Aiko, Y., Hosokawa, S., Shima, F., Kato, M., and Kitamura, K. (1988) Alterations in local cerebral glucose utilization during electrical stimulation of the striatum and globus pallidus in rats. Br. Res., 442:43-52.

Albin, R.L., Young, A.B., and Penney, J.B. (1989) The functional anatomy of basal ganglia disorders. Trends Neurosci., 12:366-375.

Anderson, L.A., Anderson, J .J ., Chase, T.N., and Walters, J .R. (1995) The cannabinoid agonists WIN 55,212-2 and CP 55,940 attenuate rotational behavior induced by a dopamine $D_{1}$ but not $\mathrm{D}_{2}$ agonist in rats with unilateral lesions of the nigrostriatal pathway. Br. Res., 691:106-114.

Costall, B., Naylor, R.J ., and Olley, J .E. (1972) Catalepsy and circling behaviour after intracerebral injections of neuroleptic, cholinergic and anticholinergic agents into the caudate-putamen, globus pallidus and substantia nigra of rat brain. Neuropharmacology, 11:645-663.

Graybiel, A.M. (1990) Neurotransmitters and neuromodulators in the basal ganglia. Trends Neurosci., 13:244-253.

Herkenham, M., Lynn, A.B., de Costa, B.R., and Richfield, E.K. (1991a) Neuronal localization of cannabinoid receptors in the basal ganglia of the rat. Brain Res., 547:267-274.

Herkenham, M., Lynn, A.B., J ohnson, M.R., Melvin, L.S., de Costa, B.R., and Rice, K.C. (1991b) Characterization and localization of cannabinoid receptor in rat brain: a quantitative in vitro autoradiographic study. J. Neurosci., 11:563-583.

Herrera-Marschitz, M., and Ungerstedt, U. (1987) The dopamine- $\gamma$ aminobutyric acid interaction in the striatum of the rat is differently regulated by dopamine D-1 and D-2 types of receptor: evidence obtained with rotational behavioural experiments. Acta Physiol Scand., 129:371-380.

Howlett, A.C. (1995) Pharmacology of cannabinoid receptors. Annu. Rev. Pharmacol. Toxicol., 35:607-634.

Kinoshita H., Hasegawa T., Kameyama T., Yamamoto I., Nabeshima T., (1994) Competitive NMDA antagonists enhance the catalepsy induced by $\Delta^{9}$-tetrahydrocannabinol in mice. Neurosci. Lett., 174: 101-104.

Klemm, W.R. (1989) Drug effects on active immobility responses: what they tell us about neurotransmitter systems and motor functions. Prog. Neurobiol., 32:403-422.

Le Moine C., Bloch B. (1995) D1 and D2 dopamine receptor gene expression in the rat stratum: sensitive cRNA probes demonstrate prominent segregation of D1 and D2 mRNAs in distinct neuronal populations of the dorsal and ventral striatum. J . Comp. Neurol. 355:418-26.

Lindvall, O., and Bjorklund, A. (1979) Dopaminergic innervation of the globus pallidus by collaterals from the nigrostriatal pathway. Br. Res, 172:169-173.

Mackie, K., and Hille, B. (1992) Cannabinoid inhibit N-type calcium channels in neuroblastoma-glioma cells. Proc. Natl. Acad. Sci., 89:3825-3829.

Mackie, K., Lai, Y., Westenbroek, R., and Mitchell, R. (1995) Cannabinoids activate an inwardly rectifying potassium conductance and inhibit Q-type calcium currents in AtT20 cells transfected with rat brain cannabinoid receptor. J . Neurosci. 15:6552-6561.

Mailleux, P., and Vanderhaeghen, J .J . (1992) Distribution of neuronal cannabinoid receptor in the adult rat brain: a comparative receptor binding radioautography and in situ hybridization histochemistry. Neuroscience, 48:655-688.

Mansour, A., Meador-Woodruff, J.H., Bunzow, J R., Civelli, O., Akil, H., and Watson, S.J. (1990) Localization of dopamine $D_{2}$ receptor mRNA and $D_{1}$ and $D_{2}$ receptor binding in the rat brain and pituitary: an in situ hybridization-receptor autoradiographic analysis. J. Neurosci., 10:2587-2600.

Mansour, A., Meador-Woodruff, J.H., Zhou, Q.H., Civelli, O., Akil, H., and Watson, S.J. (1992) A comparison of $\mathrm{D}_{1}$ receptor binding and mRNA in rat brain using receptor autoradiographic and in situ hybridization techniques. Neuroscience 46:959-997.

Meador-Woodruff, J .H., Mansour, A., Bunzow, J .R., Van Tol, H.H.M., Watson, S.J ., and Civelli, O. (1989) Distribution of $\mathrm{D}_{2}$ dopamine receptor mRNA in the rat brain. Proc. Natl. Acad. Sci., 86:7625-7628.

Miller, A., and Walker, J.M. (1995) Effects of a cannabinoid on spontaneous and evoked neuronal activity in the substantia nigra pars reticulata. Eur. J . Pharmacol., 279:179-185.

Miller, A., and Walker, J .M. (1996a) Electrophysiological effects of a cannabinoid on neural activity in the globus pallidus. Eur. J . Pharmacol., 304:29-35.

Miller, A., and Walker, J .M. (1996b) Micropressure ejection of cannabinoids into the globus pallidus. Soc. Neurosci. Abst. 22:2027.

Pertwee, R.G., and Wickens, A.P. (1991) Enhancement by chlordiazepoxide of catalepsy induced in rats by intravenous or intrapallidal injections of enantiomeric cannabinoids, Neuropharmacology, 30: 237-244.

Pucak, M.L., and Grace, A.A. (1994) Evidence that systemically administered dopamine antagonists activate dopamine neuron firing primarily by blockade of somatodendritic autoreceptors. J . Pharmacol. Exp. Ther., 271:1181-1192.

Richfield E.K., Herlxenham M. (1994) Selective vulnerability in Huntington's disease: preferential loss of cannabinoid receptors in lateral globus pallidus. Ann. Neurol., 36:577-584.

Romero, J., de Miguel, R., García-Palomero, E., Fernández-Ruiz, 」. . . and Ramos, J.A. (1995) Time-course of the effects of anandamide, the putative endogenous cannabinoid receptor ligand, on extrapyramidal function. Brain Res., 694:223-232.

Romero, J ., García-Palomero, E., Fernández-Ruiz, J .J ., and Ramos, 
J.A. (1996a) Involvement of $\mathrm{GABA}_{B}$ receptors in the motor inhibition produced by agonists of brain cannabinoid receptors. Behav. Pharmacol., 7:299-302.

Romero, J ., García-Palomero, E., Lin, S.Y., Ramos, J .A., Makriyannis, A., and Fernández-Ruiz, J.J. (1996b) Extrapyramidal effects of methanadamide, an analog of anandamide, the endogenous $\mathrm{CB}_{1}$ receptor ligand. Life Sci., 15:1249-1257.

Santiago, M., and Westerink, B.H.C. (1991) The regulation of dopamine rel ease from nigrostriatal neurons in conscious rats: the role of somatodendritic autoreceptors. Eur. J. Pharmacol. 204:79-85.

Sañudo-Peña, M.C., and Walker, J .M. (1997) Role of the subthalamic nucleus on cannabinoid actions in the substantia nigra of the rat. J . Neurophysiol, 77:1635-1638.

Sañudo-Peña, M.C., Patrick, S.L., Patrick, R.L., and Walker, J .M. (1996) Effects of intranigral cannabinoids on rotational behavior in rats: interactions with the dopaminergic system. Neurosci. Lett. 206:21-24.

Slater P., Lee L.A., Longman D.A., Crossman A.R. (1980) An in vivo method for testing putative GABA-like compounds. S. Pharmacol. Meth., 3:39-49.

Souilhac, J., Poncelet, M., Rinaldi-Carmona, M., Le-Fur, G., and Soubrie, P. (1995) Intrastriatal injection of cannabinoid receptor agonists induced turning behavior in mice. Pharmacol. Biochem. Behav., 51:3-7.
Sukul, N.C., Cherian, L., and Klemm, W.R. (1988) Alpha noradrenergic agonists promote catalepsy in the mouse. Pharmacol. Biochem. Behav., 31:87-91.

Vacherri, A., Dall'Olio, R., Gandolfi, O., and Montanaro, N. (1986) Involvement of different dopamine receptors in rat diphasic motility response to apomorphine. Psychopharmacol ogia, 89:265-268.

Wickens, A.P., and Pertwee, R.G. (1993) Delta 9-tetrahydrocannabinol and anandamide enhance the ability of muscimol to induce catalepsy in the globus pallidus of rats. Eur. J. Pharmacol., 250:205-208.

Wilson, C.J. (1993) The generation of natural firing patterns in neostriatal neurons. In: GW Arbuthnott, PC Empson, eds. Chemical Signalling in the Basal Ganglia. Progress Brain Research. Vol. 99. Elsevier, Amsterdam, pp. 277-298.

Yamaguchi K., Nabeshima T., Kameyama T. (1986) Role of dopaminergic and GABAergic mechanisms in discrete brain areas in phencyclidine-induced locomotor stimulation and turning behavior. J . Pharmacobiodyn, 9:975-986.

You, Z.B., Herrera-Marschitz, M., Nylander, I., Goiny, M., O'Connor W.T., Ungerstedt, U., and Terenius, L. (1994) The striatonigral dynorphin pathway of the rat studied with in vivo microdialysis-II. Effects of dopamine $D_{1}$ and $D_{2}$ receptor agonists. Neuroscience, 63:427-434. 